\title{
Behind a Mask: Tricks, Pitfalls, and Prejudices for Noninvasive Ventilation
}

\author{
Stefano Nava MD
}

\author{
Introduction \\ Why Was NIV Slow to Take Off? \\ The Fabulous Four \\ COPD Exacerbation \\ Cardiogenic Pulmonary Edema \\ NIV for Earlier Extubation After COPD Exacerbation \\ NIV for Respiratory Failure in Immunocompromised Patients \\ Emerging Applications \\ Prevention of Post-Surgical Complications \\ NIV in Patients With Do-Not-Intubate Orders and for Symptom Palliation \\ Asthma \\ Prevention of Extubation Failure \\ Obesity Hypoventilation Syndrome \\ Risky Business \\ Pandemic Diseases \\ ARDS \\ Real-Life Application \\ Tricks and Traps \\ And When NIV Fails? Endotracheal Intubation and New Horizons
}

It is difficult to exactly date the beginning of mechanical ventilation, but there are no doubts that noninvasive ventilation (NIV) was the first method of ventilatory support in clinical practice. The technique had a sudden increase in popularity, so that it is now considered, according to criteria of evidence-based medicine, the first-line treatment for an episode of acute respiratory failure in 4 pathologies (the Fabulous Four): COPD exacerbation, cardiogenic pulmonary edema, pulmonary infiltrates in immunocompromised patients, and in the weaning of extubated COPD patients. The so-called emerging applications are those for which the evidence has not achieved level A, mainly because the number or sample size of the published studies does not allow conclusive meta-analysis. These emerging applications are the post-surgical period, palliation of dyspnea, asthma attack, obesity hypoventilation syndrome, and to prevent extubation failure. Potentially "risky business" uses include for respiratory failure from pandemic diseases and ARDS, where probably the "secret" for success is early use. Healthcare is rich in evidence-based innovations, yet even when such innovations are implemented successfully in one location, they often disseminate slowly, if at all, so their clinical use remains limited and heterogeneous. The low rate of NIV use in some hospitals relates to lack of knowledge about or experience with NIV, insufficient confidence in the technique, lack of NIV equipment, and inadequate funding. But NIV use has been increasing around the world, thanks partly to improved technologies. The skill and confidence of clinicians in NIV have improved with time and experience, but NIV is and should remain a team effort, rather than the property of a single local "champion," because, overall, NIV is beautiful! Key words: noninvasive ventilation; respiratory failure. [Respir Care 2013;58(8):1367-1376. @ 2013 Daedalus Enterprises] 
You're wearing a mask

You look better that way

$$
\text { - Iggy Pop }
$$

\section{Introduction}

It is a great honor for me to give this lecture, and I thank the American Association for Respiratory Care (AARC) for giving me the opportunity. In particular I want to express my gratitude to Doug Laher, Ray Masferrer, Dean Hess, my paesano Sam Giordano, and Crystal Maldonado for the excellent organization.

Many clinicians think that mechanical ventilation started when the practice of endotracheal intubation took off. The first mentions of tracheotomy dates back to circa $3600 \mathrm{BC}$, in Egypt, but only for removal of a foreign body from the airway or to protect airways, the evidence for which was found on 2 Egyptian tablets. ${ }^{1}$

Tracheotomy was also described in the Rig veda, an ancient Hindu text. Homerus of Byzantium is said to have written of Alexander the Great having saved a soldier from asphyxiation by making an incision with the tip of his sword in the man's trachea. ${ }^{2}$

The Roman physician Galen may have been the first to describe mechanical ventilation: "If you take a dead animal and blow [through a reed] air through its larynx, you will fill its bronchi and watch its lungs attain the greatest distention."2 In 1908, George Poe demonstrated his mechanical respirator by asphyxiating dogs and seemingly bringing them back to life. ${ }^{2}$

In the early 1940s came the first reports of mechanical ventilation in humans, with oronasal mask, mainly for acute respiratory failure (ARF), which was the beginning of mechanical ventilation in clinical practice. ${ }^{3}$ Thus, noninvasive ventilation (NIV) preceded endotracheal intubation, and for many years NIV was the preferred method of ventilation; the "iron lung" negative-pressure ventilator was the primary ventilator during the polio pandemic in the 1950 s. ${ }^{4}$

Dr Nava is affiliated with Pneumologia e Terapia Intensiva Respiratoria, Azienda Opedaliera Universitaria Sant Orsola-Malpighi, and the Department of Specialistic, Diagnostic, and Experimental Medicine, School of Medicine, Alma Mater Studiorum Università di Bologna, Bologna, Italy.

Dr Nava presented a version of this paper as the 39th Donald F Egan Scientific Memorial Lecture at the 58th AARC Congress, held November 10-13, 2012, in New Orleans, Louisiana.

The author has disclosed no conflicts of interest.

Correspondence: Stefano Nava MD, Pneumologia e Terapia Intensiva Respiratoria, Azienda Opedaliera Universitaria Sant Orsola-Malpighi, via Massarenti no. 9, Bologna 40138 Italy. E-mail: stefano.nava@aosp.bo.it.

DOI: $10.4187 /$ respcare. 02457
However, I would point out that NIV was first used much earlier. The book of Genesis, chapter 2:7,5 states, "The Lord God formed man from the dust of the ground and breathed into his nostrils the breath of life, and man became a living being." What, then, is the beginning of life, if not the first use of NIV?

In the early 1980s NIV had a sudden "comeback," and the number of scientific publications increased dramatically, especially in the last decade, suggesting that NIV has become a hot topic in medicine.

\section{Why Was NIV Slow to Take Off?}

In the year 2000 an international consensus conference ${ }^{6}$ stated that in certain conditions NIV should be considered the first-line treatment. In 2010 an international survey ${ }^{7}$ found that about $20 \%$ of COPD patients were receiving NIV in the ICU, and that the use of NIV had dramatically increased recently in some countries, surpassing intubation as the first choice. ${ }^{8}$

Overall in Europe, the use of NIV in the ICU is about $35 \%$ of ventilated patients and about $60 \%$ in respiratory ICUs and emergency departments. ${ }^{9}$ In North America, NIV is most often begun in the emergency department, and most of these patients are transferred to ICUs or step-down units. ${ }^{10,11}$

Healthcare is rich in evidence-based innovations, yet even when such innovations are implemented successfully in one location, they often disseminate slowly, if at all. ${ }^{12}$ Diffusion of innovations is a major challenge in all industries, including healthcare, because people react differently to novelty, following a Gaussian trend, where the majority are roughly divided into early and late innovation adopters, and the rest are "innovators" on one side and "laggards" on the other.

The low rate of NIV use in some hospitals relates to lack of knowledge about or experience with NIV, mainly among the physicians rather than for the respiratory therapists; insufficient confidence in the technique, despite the scientific evidence; lack of NIV equipment (eg, NIV ventilators and sophisticated NIV interfaces); and inadequate funding. ${ }^{13}$ The main barrier to NIV use seems to be physiological factors rather than scientific reasons. We must, however, admit that applying and receiving NIV is not as easy as prescribing or taking a pill, so these physiological barriers may be partly justified or at least understandable.

\section{The Fabulous Four}

This year, 2012, the Beatles, also known as the Fabulous Four, are celebrated for their 50th anniversary. And for NIV we have the Fabulous Four NIV applications, based on recent randomized controlled trials (RCTs) and meta-analysis that have given NIV grade A evidence for 
Table 1. Relative Risk for Mortality and Endotracheal Intubation in the "Fabulous Four" Indications for NIV Versus Standard Treatment or Conventional Ventilator Weaning

\begin{tabular}{lcc}
\hline \hline & \multicolumn{2}{c}{ Relative Risk } \\
\cline { 2 - 3 } & Mortality & $\begin{array}{c}\text { Endotracheal } \\
\text { Intubation }\end{array}$ \\
\hline COPD exacerbation $^{15}$ & 0.41 & 0.42 \\
Cardiogenic pulmonary edema $^{16}$ & CPAP 0.64 & CPAP 0.43 \\
Immunocompromise $^{17}$ & NIV 0.80 & NIV 0.48 \\
Ventilator weaning in COPD $^{18}$ & 0.68 & 0.74 \\
& 0.42 & Not applicable \\
NIV = noninvasive ventilation & & \\
\hline
\end{tabular}

use in respiratory failure from COPD exacerbation, cardiogenic pulmonary edema (CPE), and immunocompromised conditions, and for ventilator weaning in patients with COPD. ${ }^{14}$ Table 1 shows the relative risks of mortality and endotracheal intubation in the studies that have compared NIV to standard treatment or conventional ventilator weaning. ${ }^{15-18}$

\section{COPD Exacerbation}

The first studies on the role of NIV in COPD patients experiencing acute hypercapnic respiratory failure were conducted in the early 1990s..$^{19,20}$ Since then, several RCTs have shown that NIV added to standard medical treatment is effective in reducing mortality, avoiding intubation, improving dyspnea, and reducing hospital stay in COPD patients with ARF, compared to standard medical management plus oxygen therapy. ${ }^{15,21-23}$ Patients treated with NIV, irrespective of their initial illness severity, had lower rates of infectious complications (ventilator-associated pneumonia, sepsis).

An RCT with 236 subjects found that the rate of success with NIV was especially high in subjects with mild acidosis $(\mathrm{pH}>7.30)$, whereas patients with more severe acidosis did not fare as well and were more likely to require intubation. ${ }^{21}$ However, 2 RCTs comparing NIV to invasive ventilation in very acidotic patients found no differences in patient outcomes, though there were fewer complications and shorter hospital stay in one investigation, ${ }^{24}$ and less requirement for tracheotomy and hospital admission in the following year in another study. ${ }^{25} \mathrm{~A}$ recent prospective study ${ }^{26}$ in the United Kingdom, with 9,716 in-patients with COPD exacerbation and ARF managed in general clinical practice, showed an overall mortality of $25 \%$ in patients receiving NIV, which is significantly higher than the figures reported in the RCTs. The study pointed to several potential explanations, including incorrect patient selection (including, in some cases, patients with mixed acidosis or prevailing metabolic acidosis), the use of NIV as a ceiling of treatment in subjects with very severe disease, and substantial delays in initiating NIV. In addition, patients with mild acidosis (in whom the effectiveness of NIV is higher) were a minority among the overall group, and they often did not receive NIV.

\section{Cardiogenic Pulmonary Edema}

$\mathrm{CPE}$ is a consequence of left ventricular failure and frequently leads to reduced lung compliance, with decreased functional residual capacity, regional atelectasis, ventilationperfusion mismatch, and poor gas exchange, resulting in lung failure with hypoxemic respiratory failure $\left(\mathrm{P}_{\mathrm{aO}_{2}}{ }^{\prime}\right.$ $\mathrm{F}_{\mathrm{IO}_{2}}<300 \mathrm{~mm} \mathrm{Hg}$ ). CPAP has long been known to improve survival and avoid intubation in CPE patients, compared to conventional treatment plus oxygen therapy.27,28 CPAP has the advantage of being practical and relatively easy to use; in most cases CPAP is begun in the emergency department.

In hypoxemic patients conventional NIV has not produced significant improvements over CPAP, although it can be effective in CPE patients exhibiting hypercapnia. ${ }^{29,30}$ However, the latter finding was recently questioned by a multicenter trial that compared oxygen therapy alone, CPAP, and NIV. ${ }^{31}$ With NIV, the physiological improvements were faster than with oxygen alone, but there was no significant effect on the intubation or mortality rates. However, the very low intubation rate in this study $(<3 \%)$ raises questions as to whether the patient population was comparable to that of other studies. A very recent metaanalysis $^{16}$ that included this large RCT confirmed that both CPAP and NIV are more effective than standard therapy in reducing the intubation rate, and that CPAP and NIV are equally effective and without important adverse effects.

\section{NIV for Earlier Extubation After COPD Exacerbation}

The first RCT of extubation to NIV after COPD exacerbation was in severely ill COPD patients. ${ }^{32}$ Patients who failed T-piece spontaneous breathing trial were randomized to either extubation and immediate NIV, or to continued intubation and ventilator weaning. NIV increased the likelihood of extubation success and shortened the duration of mechanical ventilation and ICU stay.

A second RCT, in patients with chronic respiratory disorders and intubated for $\mathrm{ARF},{ }^{33}$ found a shorter duration of intubation in the group extubated to NIV, although no differences were found in ICU or hospital stay or 3-month survival.

In a third RCT, patients who failed spontaneous breathing trials on 3 consecutive days were randomized to either extubation and NIV, or continued intubation and a con- 
ventional weaning protocol. ${ }^{34}$ Most of the patients were affected by hypercapnic respiratory failure. The NIV group had shorter duration of intubation, shorter ICU and hospital stay, lower rates of nosocomial pneumonia and septic shock, and better 90-day survival.

Unselected patients who failed T-piece spontaneous breathing trials were randomized to extubation and NIV or continued intubation and traditional weaning. The percentage of complications in the NIV group was lower, with lower incidences of pneumonia and tracheotomy. ${ }^{35}$

More recently Girault et $\mathrm{al}^{36}$ found that NIV for earlier extubation in difficult-to-wean patients with chronic respiratory failure did not reduce the reintubation rate within 7 days, as compared with conventional weaning and early extubation with standard oxygen therapy. Nevertheless, NIV may improve the weaning results in these patients by shortening the intubation duration and reducing the risk of post-extubation ARF.

In conclusion, the meta-analysis ${ }^{18}$ indicates that NIV may be safely and successfully used in the ICU for earlier extubation in stable patients recovering from hypercapnic $\mathrm{ARF}$ and who have failed spontaneous breathing trials.

\section{NIV for Respiratory Failure in Immunocompromised Patients}

An immunocompromised status, irrespective of its specific cause, often leads to serious lung infection and severe hypoxemic respiratory failure. ${ }^{37}$ Immunocompromised patients can benefit from NIV, especially since they are at particular risk of infectious complications related to endotracheal intubation and invasive ventilation. NIV, especially when applied early, can ameliorate their respiratory symptoms. NIV reduced the need for intubation in all the studies, ${ }^{38-44}$ and reduced overall mortality in studies. ${ }^{17,45}$ Indeed, according to 2 studies, ${ }^{46,47}$ NIV can even be administered to these patients by trained personnel outside the ICU to avoid the exposure risks in the ICU environment. These data provide a rationale for early NIV for respiratory failure in immunocompromised patients.

\section{Emerging Applications}

The so-called emerging applications are those for which the evidence is not level A, mainly because the small sample sizes in the published studies do not allow conclusive meta-analysis. ${ }^{48}$

\section{Prevention of Post-Surgical Complications}

Major surgeries are often complicated by postoperative hypoxemia and respiratory failure, sometimes leading to death. ${ }^{49}$ Pulmonary atelectasis after major surgery is a frequent complication and may predispose patients to pneu- monia. ${ }^{49}$ RCTs have shown that CPAP decreases atelectasis and prevents pneumonia more effectively than does standard therapy after upper abdominal surgery, ${ }^{50}$ and that NIV significantly ameliorates gas exchange and pulmonary function abnormalities after gastrosplasty in obese patients..$^{51}$ NIV after thoracic, ${ }^{52,53}$ cardiac, ${ }^{54,55}$ or vascular surgeries $^{56}$ may help prevent loss of lung volume and atelectasis, while facilitating recovery. One RCT found that NIV to treat early ARF following lung resection improved survival. ${ }^{57}$

\section{NIV in Patients With Do-Not-Intubate Orders and for Symptom Palliation}

Patients with severe irreversible disease often eschew intubation when they present with ARF, and intubation may be inappropriate if the patient is in the terminal stage. Two large United States studies on patients with ARF and do-not-intubate orders found that roughly half of the patients treated with NIV survived and were discharged from the hospital. ${ }^{58,59}$ The underlying disease was an important determinant of survival; patients with congestive heart failure had better survival rates than patients with COPD, and these were considerably better than those with pneumonia or cancer.

Concerning the use of NIV as a "sole" palliative measure to relieve dyspnea, ${ }^{60}$ a recent $\mathrm{RCT}^{61}$ found that in end-stage solid cancer patients, NIV improved dyspnea faster than did oxygen alone, and reduced the amount of morphine needed.

\section{Asthma}

Three RCTs have assessed the use of NIV during severe, non-life-threatening asthma attacks, prior to the development of ARF. The first study ${ }^{62}$ showed improved flow and fewer hospitalizations with NIV, versus sham NIV. The second study ${ }^{63}$ reported similar conclusions with high inflation pressure, but not with low pressure or with standard medical therapy. In patients with severe acute asthma, the addition of NIV to standard therapy probably accelerates the improvement in lung function, decreases the inhaled bronchodilator requirement, and shortens the stay in the ICU. ${ }^{64}$

A trial of NIV can be considered to try to prevent ARF in asthmatics who fail to respond adequately to bronchodilator. Whether or not NIV is effective to treat overt ARF in asthmatics is currently unknown.

\section{Prevention of Extubation Failure}

Post-extubation respiratory failure occurs in about $15 \%$ of extubated patients, and the in-hospital mortality is approximately $30-40 \%$. Two RCTs have found that NIV 
applied immediately after extubation in patients considered to be at high risk of extubation failure lowered the reintubation rate, and in one of the studies post-extubation NIV lowered ICU mortality in a subgroup of patients with hypercapnia. ${ }^{65,66}$ Another $\mathrm{RCT}^{67}$ in patients with hypercapnia at the time of extubation prospectively confirmed the latter findings, but these results were not confirmed when NIV was applied to all patients after extubation, without selecting the patients at higher risk. ${ }^{68}$ Two other earlier RCTs tested the hypothesis that NIV could avoid reintubation in patents already showing signs of acute respiratory distress within the first 48 hours after extubation, but found no reduction in reintubation rate, ${ }^{69}$ and one ${ }^{70}$ even found significantly higher ICU mortality in the NIV group, associated with longer delay in reintubation. Interestingly enough, a pilot study performed in patients extubated early after hypoxic respiratory failure showed that NIV was very useful as a bridge to unsupported breathing, reducing the frequency of post-extubation failure. ${ }^{71}$ In conclusion, although controversial, the accumulating evidence suggests that NIV has a role in treating extubation failure, but mainly in hypercapnic and congestive heart failure patients who are at high risk for extubation failure. ${ }^{72}$

\section{Obesity Hypoventilation Syndrome}

Obesity is an epidemic health and socioeconomic problem in many countries, and predisposes patients to chronic alveolar hypoventilation, usually in association with obstructive sleep apnea. Some case reports and observational studies $^{73-75}$ suggest that in this situation NIV can ameliorate the alveolar hypoventilation and avoid intubation, but so far RCTs are lacking.

\section{Risky Business}

\section{Pandemic Diseases}

One potential application of NIV is for ARF caused by pandemic diseases such as severe acute respiratory syndrome (SARS). Based on the Toronto experience with SARS, ${ }^{76}$ in which some clinicians contracted SARS during intubation of patients who failed NIV, the use of NIV was discouraged because of infection risk, but this was recently challenged by Simonds et al, ${ }^{77}$ who found that the droplets generated during NIV are $>10 \mu \mathrm{m}$, so that they are not likely to remain airborne.

As shown in Table 2, in the investigations that have enrolled at least 40 patients receiving mechanical ventilation for ARF due to H1N1 flu, NIV was used, outside North America, as the first-line treatment in about $40 \%$ of patients. The success rate was very different between the studies, ranging from $23 \%$ to $76 \%$, which highlights
Table 2. NIV Use and Success in Patients With Acute Respiratory Failure and H1N1 Infection

\begin{tabular}{llcc}
\hline \hline First Author & \multicolumn{1}{c}{ Countries } & $\begin{array}{c}\text { NIV Use } \\
\text { no. (\%) }\end{array}$ & $\begin{array}{c}\text { NIV Success } \\
\text { no. (\%) }\end{array}$ \\
\hline Estenssoro $^{78}$ & Argentina & $64 / 337(18.9)$ & $43 / 64(67)$ \\
Nin $^{79}$ & Spain, Chile, and Uruguay & $43 / 96(44.7)$ & $10 / 43(23)$ \\
Teke $^{80}$ & Turkey & $42 / 66(63.6)$ & $27 / 42(64)$ \\
Mascians $^{81}$ & Spain & $177 / 489(37)$ & $72 / 177(41)$ \\
Nicolini $^{82}$ & Italy & $60 / 98(61)$ & $46 / 60(76)$
\end{tabular}

$\overline{\mathrm{NIV}}=$ noninvasive ventilation

that several factors probably influenced the different patient outcomes. ${ }^{78-82}$

Estenssoro et al ${ }^{78}$ studied 337 mechanically ventilated patients with ARF due to H1N1 pneumonia. Sixty-four received NIV, and despite the relative low success rate, NIV was associated with better outcomes, possibly because the attending physicians selected NIV for the less hypoxemic patients. In all the studies the avoidance of intubation was associated with significantly fewer infectious complications, mainly sepsis and septic shock, but also catheter-related infections.

\section{ARDS}

Few clinical trials have evaluated NIV as a means to prevent intubation in patients with mild to moderate ARDS, according to the new Berlin definition (ie, $\mathrm{P}_{\mathrm{aO}_{2}} / \mathrm{F}_{\mathrm{IO}_{2}}$ $>200 \mathrm{~mm} \mathrm{Hg}$ ). ${ }^{83}$ The results have been controversial. ${ }^{84-87}$ Most of the studies enrolled patients who did not have indications that would mandate immediate endotracheal intubation under today's standard of care.

In a recent $\mathrm{RCT}^{87}$ performed to assess the efficacy of early NIV, Zhan et al found that the proportion of patients requiring intubation was significantly lower than that in the control group (1/21 for NIV vs 7/19 for standard oxygen treatment). In more severely ill patients, Rana et al found a high failure rate and a higher than expected mortality, especially in the subgroup of patients with underlying shock, metabolic acidosis, and severe hypoxemia. ${ }^{85}$

Antonelli et al, 88 in 3 European ICUs with NIV expertise, clarified the real-life use of NIV in ARDS patients. Only $17 \%$ of the patients admitted with ARDS were successfully treated with NIV. Over 2 years, 479 patients were admitted to the 3 ICUs, and 332 (69\%) of those patients were already intubated at admission, so 147 were eligible for the study. NIV improved gas exchange and avoided intubation in 79 (54\%) of those 147 patients, so the overall NIV success rate was about $20 \%$. This was associated with less ventilator-associated pneumonia and lower ICU mortality (6\% vs 53\%). 
Behind a Mask: Tricks, Pitfalls, and Prejudices for Noninvasive Ventilation

Table 3. Actual and Perceived Use of NIV as First-Line Treatment: 2006-2012

\begin{tabular}{lllll}
\hline \hline First Author & Year & \multicolumn{1}{c}{ Country or Region } & Clinical Setting & NIV Use \\
\hline Demoule $^{8}$ & 2006 & France & ICU & Actual $52 \%$ \\
Esteban $^{7}$ & 2008 & Europe, North and South America & ICU & Actual $11 \%$ \\
Crimi $^{9}$ & 2010 & Europe & ICU & Perceived $\sim 30 \%$ \\
& & & Respiratory ICU & Perceived $\sim 75 \%$ \\
& & & Emergency department & Perceived $\sim 55 \%$ \\
Crimi $^{89}$ & 2011 & Italy & ICU & Perceived $\sim 20 \%$ \\
& & & Respiratory ICU & Perceived $\sim 80 \%$ \\
Salvade $^{90}$ & 2012 & Switzerland & ER & Perceived $\sim 65 \%$ \\
Chandra $^{91}$ & 2012 & United States & ICU & Perceived 26\% \\
Bierer $^{11}$ & 2009 & United States & Not specified & Actual $\sim 55 \%$ of COPD patients \\
& & & Emergency department & Actual 76\% of COPD patients
\end{tabular}

$\overline{\mathrm{NIV}}=$ noninvasive ventilation

In summary, as an alternative to invasive ventilation in severely hypoxemic patients with ARDS (ie, $\mathrm{P}_{\mathrm{aO}_{2}} / \mathrm{F}_{\mathrm{IO}_{2}}$ $<200 \mathrm{~mm} \mathrm{Hg}$ ), NIV is not generally advisable and should be limited to hemodynamically stable patients who can be closely monitored in an ICU by highly skilled staff.

\section{Real-Life Application}

As shown in Table 3, the utilization of NIV differs greatly between hospitals and geographic regions, and has been changing. . $^{7,911,89-91}$ A worldwide prospective survey on mechanical ventilation in ICUs found that NIV use rose from $4 \%$ of all ventilator starts in 2001 to $11 \%$ in $2004 .^{7}$ NIV is increasingly being used in many countries, but NIV use remains highly variable. It is used mainly for COPD exacerbations and $\mathrm{CPE}^{89,90,92-94}$; use for hypoxic respiratory failure and earlier extubation is still infrequent and mainly at specialized centers. ${ }^{9}$

In Europe the rate of NIV use in ICUs is approximately $35 \%$ of ventilated patients, and $60 \%$ in respiratory ICUs and emergency departments. ${ }^{9}, 94$ In some places (eg, France) the use of NIV in patients initiating any form of mechanical ventilation in the ICU has surpassed intubation, irrespective of the underlying pathology. ${ }^{8}$ A recent study performed over 10 years in the United States ${ }^{91}$ found that in 2008 NIV surpassed intubation as the most frequently used ventilatory support in patients with COPD exacerbation. The low NIV utilization rate in some hospitals is related to lack of knowledge about or experience with NIV, insufficient NIV equipment, and lack of funding. Geographical reasons may also explain the inhomogeneous pattern of NIV utilization around the world. In Europe, for example, NIV seems to be more popular than elsewhere, perhaps because the first RCTs were performed in France and the United Kingdom..$^{20,21}$ It may be more popular there also because the physician has the direct responsibility in ordering and applying NIV with the support of all the staff, including nurses and respiratory therapists, while in most other continents the prescription is basically ordered by the physician but is independently applied by the respiratory therapist; this might affect the teamwork. In the last few years NIV use has "taken off," maybe because of improved NIV equipment, such as sophisticated ventilator algorithms able to compensate for leaks, and new NIV interfaces..$^{95,96}$ NIV is being applied more often outside of ICUs and respiratory ICUs, including in emergency departments; post-surgical recovery rooms; cardiology, neurology, and oncology wards; and palliative care units.

\section{Tricks and Traps}

Air leak is a typical feature of NIV. Intentional leak is generated with a single-limb circuit that does not have a true expiratory valve. Leak is one of the most important factors affecting patient-ventilator synchrony. ${ }^{97}$ When choosing the NIV interface, great consideration should be given to minimizing unintentional leak, ${ }^{98}$ which impairs NIV efficiency, ${ }^{99-102}$ particularly during the first few hours of ventilation, when the patient is adapting to NIV, and during sleep, due to the loss of voluntary muscle control and decreased muscle tone. Interventions to reduce air leak include mask-support ring; ensuring proper interface type, size, and securing system; and optimizing patient comfort and efficiency with, for instance, hydrogel or foam seal, lip seal or mouth taping, and/or chin strap. Tightening the straps to reduce leak can decrease patient comfort and tolerance and increase the risk of skin ulcers, while not necessarily decreasing the amount of leak. ${ }^{98}$ Unfortunately, air leak may still exist despite the above interventions. Ventilators specifically designed for NIV, as well as ICU ventilators with an NIV module, are designed to compensate for air leak, but there is high variability among such ventilators. ${ }^{101,102}$ The best performance, tested both in vivo and in vitro, in patient-ventilator interaction, has been with 
the ventilators specifically designed for NIV, versus ICU ventilators or transport ventilators. ${ }^{102}$

When starting NIV, the clinicians should always consider that the patient needs to maintain at least a minimal respiratory capacity. We can face 2 extremes: the first is when the patient is comatose but still able to breathe by her/himself (ie, due to the effect of severe hypercapnia); the second is when the respiratory drive is abnormally increased due to anxiety and diaphoresis. Hypercapnic encephalopathy has been considered a relative contraindication to NIV because of the perceived risk of pulmonary aspiration and lack of cooperation. ${ }^{14}$ However, several uncontrolled studies have suggested that NIV is highly successful in avoiding endotracheal intubation in patients with hypercapnic ARF and severely impaired consciousness. ${ }^{103,104}$ Moreover, a case-control study ${ }^{105}$ by an experienced team found that NIV and invasive ventilation had similar short- and long-term survival, and that NIV had a lower nosocomial infection rate and a shorter duration of ventilation.

In patients with high respiratory demand, especially in the first phase of NIV application, reducing the respiratory drive is desirable, and sedative can be used, but this indication has to be balanced with the risks associated with hampering the sensorium and the patient's capacity to maintain spontaneous breathing. ${ }^{106}$ Remifentanil is a new synthetic opioid that provides a good compromise between reducing the respiratory drive and maintaining breathing capacity, which can improve NIV tolerance. Remifentanil's advantages include a constant and short, context-sensitive plasma half-life that allows prompt recovery after stopping the infusion. Two clinical studies have suggested that a remifentanil-based sedation protocol decreased NIV intolerance. ${ }^{107,108}$

\section{And When NIV Fails? Endotracheal Intubation and New Horizons}

If, despite skillful NIV application and maximal medical management, respiratory distress, gas exchange, consciousness, tachypnea, and/or acidosis worsen, then tracheal intubation becomes mandatory However, tracheal intubation and invasive ventilation have adverse effects associated with higher morbidity and mortality in COPD patients, so reducing the intubation rate should improve several outcomes. Recently, new extracorporeal $\mathrm{CO}_{2^{-}}$ removal devices that work at different extracorporeal blood flows have been developed ${ }^{109,110}$ using a veno-venous system, double-lumen catheter, and $\mathrm{CO}_{2}$ transfer membranes within a standard device for renal replacement therapy. They work with a low blood flow: $<0.5 \mathrm{~mL} / \mathrm{min}$ with the 14 French catheter, or $>1 \mathrm{~mL} / \mathrm{min}$ with the 18 French catheter). Preliminary studies found that this device obviated intubation in about $80 \%$ of the patients who failed
NIV. If that is confirmed in an RCT, we may be able to rethink our strategy for COPD exacerbation, in 4 steps: medical therapy when ARF is not yet present; NIV for patients presenting with a $\mathrm{pH}<7.35$; extracorporeal $\mathrm{CO}_{2}$ removal for patients who fail NIV; and intubation in the remaining patients.

\section{ACKNOWLEDGMENTS}

It was an honor for me to give this lecture, and I thank all the people who helped make the dreams of a young medical student, back in 1975, to come true. First of all I thank my patients, for their love, for their strength in carrying on in the burden of their disease, and for letting me understand their pain, handicap, suffering, and what it means to be sick. I am also indebted to all the people I work with and learn from. I am a rather unusual Italian, having changed employers several times, but as Nick Cave said, "The game is not won by standing in any one place for too long."111

In particular I want to mention: Joseph Milic-Emili, Peter Macklem (in memoriam), and François Bellemare (the Canadian good old times); Ciro Rampulla, Renato Corsico, Claudio Fracchia, Nicolino Ambrosino, and Fiorenzo Rubini (our fantastic experience in Montescano, where our adventure with NIV started); Annalisa Carlucci, Serena Cirio, Giancarlo Piaggi and Piero Ceriana (the "maturity" period in Pavia); Nicholas Hill (the Boston sabbatical); Lara Pisani and Luca Fasano (the ICU team in Bologna); Paolo Navalesi, Cesare Gregoretti, Massimo Antonelli, Giorgio Conti, Edo Calderini, Massimo Gorini (in memoriam); Giorgio Iotti and Giuseppe Foti (the Italian mechanical ventilation group since the early 1990s); and Marco Ranieri (for his support during a difficult trip).

I am also grateful to all my teammates of the various sports that I have practiced during my life, since in the locker room I learned how to build the teamwork I use during my clinical work. In particular I want to mention my first soccer coach, who told me, "Soccer is not your sport." Well, 45 years later I'm still playing every week, alive and kicking!

Last, but not least, I need to mention my family. My old parents, Mafalda and Angelo, for teaching me perseverance, my Cavalier King Charles Spaniel, Ralph, for always being happy to see me, and my wife, Anna Maria, for supporting me daily.

At the real end on the notes of "Every teardrop is a waterfall," I want to thank all of you for your attention, and, remember, I am a proud member of the AARC.

\section{REFERENCES}

1. Sittig SE, Pringnitz JE. Tracheostomy: evolution of an airways. AARC Times 2001;25(2):48-51.

2. Ferlito A, Rinaldo A, Shaha AR, Bradley PJ. Percutaneous tracheotomy. Acta Otolaryngol 2003;123(9):1008-1012.

3. Barach AL, Eckman M. Studies on positive pressure respiration; general aspects and types of pressure breathing; effects on respiration and circulation at sea level. J Aviat Med 1946;17:290-232.

4. Geddes LA. The history of artificial respiration. IEEE Eng Med Biol Mag 2007;26(6):38-41.

5. Hamilton, Victor P. The book of Genesis. Grand Rapids, Michigan: Eerdmans Publishing; 1990:154-159.

6. International Consensus Conferences in Intensive Care Medicine. Noninvasive positive pressure ventilation in acute respiratory failure. Am J Respir Crit Care Med 2001;163(1):283-291.

7. Esteban A, Ferguson ND, Meade MO, Frutos-Vivar F, Apezteguía $\mathrm{C}$, Brochard L, et al. Evolution of mechanical ventilation in response to clinical research. Am J Respir Crit Care Med 2008; 177(2):170-177. 
8. Demoule A, Girou E, Richard JC. Taillé S, Brochard L. Increased use of noninvasive ventilation in French intensive care units. Intensive Care Med 2006;32(11):1747-55.

9. Crimi C, Noto A, Princi P, Esquinas A, Nava S. A European survey of noninvasive ventilation practices Eur Respir J 2010;36(2): 362-369.

10. Hess DR, Pang JM, Camargo CA Jr. A survey of the use of noninvasive ventilation in academic emergency departments in the United States. Respir Care 2009;54(10):1306-1312.

11. Bierer GB, Soo Hoo GW. Noninvasive ventilation for acute respiratory failure: a national survey of Veterans Affairs hospitals. Respir Care 2009;54(10):1313-1320.

12. Berwick DM. Disseminating innovations in health care. JAMA 2003;289(15):1969-1975.

13. Maheshwari V, Paioli D, Rothaar R, Hill NS. Utilization of noninvasive ventilation in acute care hospitals: a regional survey. Chest 2006;129(5):1226-1233.

14. Nava S, Hill N. Non-invasive ventilation in acute respiratory failure. Lancet 2009;374(9685):250-259.

15. Lightowler JV, Wedzicha JA, Elliott MW, Ram FS. Non-invasive positive pressure ventilation to treat respiratory failure resulting from exacerbations of chronic obstructive pulmonary disease: Cochrane systematic review and meta-analysis. BMJ 2003; 326(7382):185-189.

16. Mariani J, Macchia A, Belziti C, Deabreu M, Gagliardi J, Doval H, et al. Noninvasive ventilation in a acute cardiogenic pulmonary edema: a meta-analysis of randomized controller study. J Cardiac Fail 2011;17(10):850-859.

17. Hilbert G, Gruson D, Vargas F, Valentino R, Gbikpi-Benissan G, Dupon $\mathrm{M}$, et al. Noninvasive ventilation in immunosuppressed patients with pulmonary infiltrates, fever, and acute respiratory failure. N Engl J Med 2001;344(7):481-487.

18. Burns KE, Adhikari NK, Keenan SP, Meade M. Use of noninvasive ventilation to wean critically ill adults off invasive ventilation: meta-analysis and systematic review. BMJ 2009;338:b1574.

19. Meduri GU, Abou-Shala N, Fox RC, Jones CB, Leeper KV, Wunderink RG. Non-invasive face mask ventilation in patients with acute hypercapnic respiratory failure. Chest 1991;100(2):445-454.

20. Brochard L, Isabey D, Piquet J, Amaro P, Mancebo J, Messadi AA. Reversal of acute exacerbations of chronic obstructive lung disease by inspiratory assistance with a face mask. N Engl J Med 1990; 323(22):1523-1530.

21. Plant PK, Owen JL, Elliott MW. A multicentre randomised controlled trial of the early use of non-invasive ventilation in acute exacerbation of chronic obstructive pulmonary disease on general respiratory wards. Lancet 2000;355(9219):1931-1935.

22. Kramer N, Meyer TJ, Meharg J, Cece RD, Hill NS. Randomized, prospective trial of noninvasive positive pressure ventilation in acute respiratory failure. Am J Respir Crit Care Med 1995;151(6): 1799-1806.

23. Keenan SP, Sinuff T, Cook DJ, Hill N. When is the addition of noninvasive positive pressure ventilation effective in acute exacerbations of COPD? A systematic review. Ann Intern Med 2003; 138(11):861-870.

24. Jurjevć M, Matić I, Sakić-Zdravević K, Sakić S, Danić D, Buković D. Mechanical ventilation in chronic obstructive pulmonary disease patients, noninvasive vs invasive method (randomized prospective study). Coll Antropol 2009;33(3):791-797.

25. Conti G, Antonelli M, Navalesi P, Rocco M, Bufi M, Spadetta G, et al. Noninvasive vs conventional mechanical ventilation in patients with chronic obstructive pulmonary disease after failure of medical treatment in the ward: a randomized trial. Intensive Care Med 2002;28(12):1701-1707.
26. Roberts CM, Stone RA, Buckingham RJ, Pursey NA, Lowe D; on behalf of the National COPD Resources and Outcome Project Implementation Group. Acidosis, non-invasive ventilation and mortality in hospitalised COPD exacerbations. Thorax 2011;66(1): 43-48.

27. Peter JV, Moran JL, Phillips-Hughes J, Graham P, Bersten AD. Effect of non-invasive positive pressure ventilation on mortality in patients with acute cardiogenic pulmonary oedema: a metaanalysis. Lancet 2006;367(9517):1155-1163.

28. Winck JC, Azevedo LF, Costa-Pereira A, Antonelli M, Wyatt JC. Efficacy and safety of non-invasive ventilation in the treatment of acute cardiogenic pulmonary edema: a systematic review and metaanalysis. Crit Care 2006;10(2):R69.

29. Masip J, Betbese AJ, Paez J, Cañizares R, Padró J, Paz MA, et al. Non-invasive pressure support ventilation versus conventional oxygen therapy in acute cardiogenic pulmonary oedema: a randomised trial. Lancet 2000;356(9248):2126-2132.

30. Nava S, Carbone G, Dibattista N, Bellone A, Baiardi P, Cosentini $\mathrm{R}$, et al. Noninvasive ventilation in cardiogenic pulmonary edema: a multicenter, randomized trial. Am J Respir Crit Care Med 2003; 168(12):1432-1437.

31. Gray A, Goodacre S, Newby DE, Masson M, Sampson F, Nicholl $\mathrm{J}$; 3CPO Trialists. Noninvasive ventilation in acute cardiogenic pulmonary edema. N Engl J Med 2008;359(2):142-151.

32. Nava S, Ambrosino N, Clini E, Prato M, Orlando G, Vitacca M, et al. Noninvasive mechanical ventilation in the weaning of patients with respiratory failure due to chronic obstructive pulmonary disease. A randomized, controlled trial. Ann Intern Med 1998;128(9): 721-728.

33. Girault C, Daudenthun I, Chevron V, Tamion F, Leroy J, Bonmarchand G. Noninvasive ventilation as a systematic extubation and weaning technique in acute-on-chronic respiratory failure. A prospective, randomized controlled study. Am J Respir Crit Care Med 1999;160(1):86-92.

34. Ferrer M, Esquinas A, Arancibia F, Bauer TT, Gonzalez G, Carrillo A, et al. Non invasive ventilation during persistent weaning failure. Am J Respir Crit Care Med 2003;168(1):70-76.

35. Trevisan CE, Vieira SR; Research Group in Mechanical Ventilation Weaning. Noninvasive mechanical ventilation may be useful in treating patients who fail weaning from invasive mechanical ventilation: a randomized clinical trial. Crit Care 2008;12(2):R51.

36. Girault C, Bubenheim M, Benichou J, Bonmarchand G. Non invasive ventilation and weaning from mechanical ventilation in chronic respiratory failure patients: the VENISE study: preliminary results Am J Respir Crit Care Med 2011;184(6):672-679.

37. Ewing S, Torres A, Riquelme R. Pulmonary complications in patients with haematological malignancies treated at a respiratory ICU. Eur Respir J 1988;12(7):116-122.

38. Antonelli M, Conti G, Bufi M, Costa MG, Lappa A, Rocco M, et al. Noninvasive ventilation for treatment of acute respiratory failure in patients undergoing solid organ transplantation: a randomized trial. JAMA 2000;12(2):235-241.

39. Adda M, Coquet I, Darmon M, Thiery G, Schlemmer B, Azoulay E. Predictors of non-invasive ventilation failure in patients with hematologic malignancy and acute respiratory failure. Crit Care Med 2008;36(10):2766-2772.

40. Gachot B, Clair B, Wolff M, Reigner B, Vachon F. Continuous positive airway pressure administered by face mask or mechanical ventilation in patients with immunodeficiency virus infection and severe Pneumocystis carinii pneumonia. Intens Care Med 1992; 18(3):155-159.

41. Conti G, Marino P, Cogliati A, Dell'Utri D, Lappa A, Rosa G, et al. Noninvasive ventilation for treatment of acute respiratory failure in 
patients with haematological malignancies: a pilot study. Intensive Care Med 1998;24(12):1283-1288.

42. Depuydt PO, Benoit DD, Wandewoude KH, Decruyenaere JM, Colardyn FA. Outcome in noninvasively and invasively ventilated hematologic patients with acute respiratory failure. Chest 2004; 126(4):1299-1306.

43. Rabitsch W, Staudinger T, Locker GJ, Köstler WJ, Laczika K, Frass M, et al. Respiratory failure after stem cell transplantation: improved outcome with non-invasive ventilation. Leuk Lymphoma 2005;46(8):1151-1157.

44. Hilbert G, Gruson D, Vargas F, Valentino R, Chene G, Boiron JM, et al. Noninvasive continuous positive airway pressure in neutropenic patients with acute respiratory failure requiring ICU admission. Crit Care Med 2000;28(9):3185-3190.

45. Azoulay E, Alberti C, Bornstain C, Leleu G, Moreau D, Recher C, et al. Improved survival in cancer patients requiring mechanical ventilator support: impact of noninvasive mechanical ventilator support. Crit Care Med 2001 29(3):519-524.

46. Principi T, Pantanetti S, Catani F, Elisei D, Gabbanelli V, et al. Noninvasive continuous positive airway pressure delivered by helmet in hematological malignancy patients with hypoxemic acute respiratory failure. Intensive Care Med 2004;30(1):147-150.

47. Squadrone V, Massaia M, Bruno B, Marmont F, Falda M, Bagna C, et al. Early CPAP prevents evolution of acute lung injury in patients with hematologic malignancy. Intensive Care Med 2010;36(10): 1666-1674.

48. Ambrosino N, Guarracino F. Unusual applications of non invasive Ventilation Eur Respir J 2011;38(2):440-449.

49. Chiumello D, Chevallard G, Gregoretti C. Non-invasive ventilation in postoperative patients: a systematic review. Intensive Care Med 2011;37(6):918-929.

50. Squadrone V, Coha M, Cerutti E, Schellino MM, Biolino P, Occella $\mathrm{P}$ et al. Continuous positive airway pressure for treatment of postoperative hypoxemia. JAMA 2005;293(5):589-595.

51. Joris JL, Sottiaux TM, Chiche JD, Desaive CJ, Lamy ML. Effect of bi-level positive airway pressure nasal ventilation on the postoperative pulmonary restrictive syndrome in obese patients undergoing gastroplasty. Chest 1997;111(3):665-670.

52. Ricksten SE, Bengstsson A, Soderberg C, Thorden M, Kvist H. Effects of periodic positive airway pressure by mask on postoperative pulmonary function. Chest 1986;89(6):774-781.

53. Aguilo R, Togores B, Pons S, Rubí M, Barbé F, Agustí AG. Noninvasive ventilatory support after lung resectional surgery. Chest 1997;112(1):117-121.

54. Matte P, Jacquet L, Van Dick M, Goenen M. Effects of conventional physiotherapy, continuous positive airway pressure and noninvasive ventilatory support with bilevel positive airway pressure after coronary artery bypass grafting. Acta Anaesthesiol Scand 2000; 44(1):75-81.

55. Pinilla JC, Oleniuk FH, Tan L, Rebeyka I, Tanna N, Wilkinson A, et al. Use of nasal continuous positive airway pressure mask in the treatment of postoperative atelectasis in aortocoronary bypass surgery. Crit Care Med 1990;18(8):836-840.

56. Kindgen-Milles D, Muller E, Buhl R, Böhner H, Ritter D, Sandmann W, et al. Nasal-continuous airway pressure reduces pulmonary morbidity and length of hospital stay following thoraco abdominal aortic surgery Chest 2005;128(2):821-828.

57. Auriant I, Jallot A, Hervé P, Cerrina J, Le Roy Ladurie F, Fournier $\mathrm{JL}$ et Noninvasive ventilation reduces mortality in acute respiratory failure following lung resection. Am J Respir Crit Care Med 2001; 164(7):1231-1235.

58. Levy M, Tanios MA, Nelson D, Short K, Senechia A, Vespia J, et al. Outcomes of patients with do-not-intubate orders treated with noninvasive ventilation. Crit Care Med 2004;32(10):2002-2007.
59. Schettino G, Altobelli N, Kacmarek RM. Noninvasive positive pressure ventilation reverses acute respiratory failure in selected "donot-intubate" patients. Crit Care Med 2005;33(10):1976-1982.

60. Cuomo AM, Conti G, Delmastro M, Antonelli M, Ceriana P, Iacobone E, et al. Noninvasive mechanical ventilation as a palliative treatment of acute respiratory failure in patients with end-stage solid cancer Palliat Med 2004;18(7):602-610.

61. Nava S, Ferrer M, Esquinas A, Scala R, Groff P, Cosentini R et al. Palliative use of non-invasive ventilation in end-of-life patients with solid cancer: a randomised feasibility trial. Lancet Onc 2013; 14(3):219-227.

62. Soroksky A, Stav D, Shpirer I. A pilot, prospective, randomized, placebo-controlled trial of bilevel positive airway pressure in acute asthmatic attack. Chest 2003;123(4):1018-1025.

63. Soma T, Hino M, Kida K, Kudoh S. A prospective and randomized study for improvement of acute asthma by non-invasive positive pressure ventilation (NPPV). Inter Med 2008;47(6):493-501.

64. Gupta D, Nath A, Agarwal R, Behera D. A prospective randomized controlled trial on the efficacy of noninvasive ventilation in severe acute asthma. Respir Care 2010;55(5):536-543.

65. Nava S, Gregoretti C, Fanfulla F, Fanfulla F, Grassi M, Beltrame F, et al. Noninvasive ventilation to prevent respiratory failure after extubation in high risk patients Crit Care Med 2005;33(11):2465-2470.

66. Ferrer M, Valencia M, Nicolas JM, Bernadich O, Badia JR, Torres A. et al. Early non-invasive ventilation averts extubation failure in patients at risk: a randomized trial. Am J Respir Crit Care Med 2006;173(2):164-170.

67. Ferrer M, Sellarés J, Valencia M, Carrillo A, Gonzalez G, Badia JR, et al. Non-invasive ventilation after extubation in hypercapnic patients with chronic respiratory disorders: randomised controlled trial. Lancet 2009;374(9695):1082-1088.

68. Su CL, Chiang LL, Yang SH, Lin HI, Cheng KC, Huang YC, $\mathrm{Wu} \mathrm{CP}$. Preventive use of noninvasive ventilation after extubation: a prospective, multicenter randomized controlled trial. Respir Care 2012;57(2):204-210.

69. Keenan SP, Powers C, McCormack DG, Block G. Noninvasive positive-pressure ventilation for postextubation respiratory distress. JAMA 2002;287(24):3238-3244.

70. Esteban A, Frutos-Vivar F, Ferguson ND, Arabi Y, Apezteguía C, Gonzales $\mathrm{M}$, et al. Non-invasive positive pressure ventilation for respiratory failure after extubation. N Engl J Med 2004;350(24): 2452-2460.

71. Vaschetto R, Turucz E, Dellapiazza F, Guido S, Colombo D, Cammarota G, et al. Noninvasive ventilation after early extubation in patients recovering from hypoxemic acute respiratory failure: a single-centre feasibility study. Intensive Care Med Care 2012; 38(10):1599-1606.

72. Epstein SK, Durbin CG. Should a patient be extubated and placed on noninvasive ventilation after failing a spontaneous breathing trial? Respir Care 2010;55(2):198-206.

73. Nelson JA, Loredo JS, Acosta JA. The Obesity-Hypoventilation Syndrome and respiratory failure in the acute trauma patient. J Emerg Med 2011;40(4):e67-e69. DOI: 10.1015/j.jemermed.2007.12.022.

74. Pérez de Llano LA, Golpe R, Ortiz Piquer M, Veres Racamonde A, Vázquez Caruncho M, Caballero Muinelos O, et al. Short-term and long-term effects of nasal intermittent positive pressure ventilation in patients with obesity-hypoventilation syndrome. Chest 2005; 128(2):587-594.

75. Guo YF, Sforza E, Janssens JP. Respiratory patterns during sleep in obesity-hypoventilation patients treated with nocturnal pressure support: a preliminary report. Chest 2007;131(4):1090-1099.

76. Poutanen SM, Low DE, Henry B, Finkelstein S, Rose D, Green K, et al. Identification of severe acute respiratory syndrome in Canada. N Engl J Med 2003;348(20):1195-2005. 
77. Simonds AK, Hanak A, Chatwin M, Morrell M, Hall A, Parker KH, et al. Evaluation of droplet dispersion during non-invasive ventilation, oxygen therapy, nebuliser treatment and chest physiotherapy in clinical practice: implications for management of pandemic influenza and other airborne infections. Health Technol Assess 2010; 14(46):131-172.

78. Estennsoro E, Rios FG, Apezteguia C, Reina R, Neira J, Ceraso DH, et al. Pandemic 2009 influenza A in Argentina: a study of 337 patients on mechanical ventilation. Am J Respir Crit Care Med 2010;182(1):41-48.

79. Nin N, Soto L, Hurtado J, Lorente JA, Buroni M, Arancibia F, et al. Clinical characteristics and outcomes of patients with 2009 influenza A (H1N1) virus infection with respiratory failure requiring mechanical ventilation. J Crit Care 2011;26(2):186-192.

80. Teke T, Coskun R, Sungur M, Guven M, Bekci TT, Maden E, et al. 2009 H1N1 influenza and experience in three critical care units. Int J Med Sci 2011;8(3):270-277.

81. Masclans JR, Pérez M, Almirall J, Lorente L, Marqués A, Socias L, et al; H1N1 GTEI/SEMICYUC Investigators. Early non-invasive ventilation treatment for severe influenza pneumonia. Clin Microbiol Infect 2013;19(3):249-256.

82. Nicolini A, Tonveronachi E, Navalesi P, Antonelli M, Valentini I, Melotti RM, et al. Effectiveness and predictors of success of noninvasive ventilation during H1N1 pandemics: a multicenter study. Minerva Anestesiol 2012;78(12):1333-1340.

83. ARDS Definition Task Force; Ranieri VM, Rubenfeld GD, Thompson BT, Ferguson ND, Caldwell E, Fan E, et al. Acute respiratory distress syndrome: the Berlin Definition. JAMA 2012;307(23): 2526-2533.

84. Rocker GM, Mackenzie MG, Williams B, Logan PM. Noninvasive pressure support ventilation: successful outcome in patients with acute lung injury/ARDS. Chest 1999;115(1):173-177.

85. Rana S, Jenad H, Gay P, Buck C, Hubmayr R, Gajic O. Failure of non-invasive ventilation in patients with acute lung injury: observational cohort study. Crit Care 2006;(10):R79.

86. Domenighetti G, Moccia A, Gayer R. Noninvasive ventilation in patients with a primary acute respiratory distress syndrome. An observational case-control study in a homogeneous group of patients. Monaldi Arch Chest Dis 2008;69(1):5-10.

87. Zhan Q, Sun B, Liang L, Yan X, Zhang L, Yang J, et al. Early use of noninvasive positive pressure ventilation for acute lung injury: a multicenter randomized controlled trial. Crit Care Med 2012;40(2): 455-460.

88. Antonelli M, Conti G, Esquinas A, Montini L, Maggiore SM, Bello $\mathrm{G}$, et al. A multiple-center survey on the use in clinical practice of noninvasive ventilation as a first-line intervention for acute respiratory distress syndrome. Crit Care Med 2007;35(1):18-25.

89. Crimi C, Noto A, Princi P, Nava S. Survey of non-invasive ventilation practices: a snapshot of Italian practice. Minerva Anestesiol 2011;77(10):971-978.

90. Salvadè I, Domenighetti G, Jolliet P, Maggiorini M, Rothen HU. Perception of non-invasive ventilation in adult Swiss intensive care units. Swiss Med Wkly 2012;142:w13551. DOI: 10.4414/smw.2012.13551.

91. Chandra D, Stamm JA, Taylor B, Ramos RM, Satterwhite L, Krishnan JA, et al. Outcomes of noninvasive ventilation for acute exacerbations of chronic obstructive pulmonary disease in the United States, 1998-2008. Am J Respir Crit Care Med 2012;185(2): 152-159.

92. Carlucci A, Richard JC, Wysochy M, Lepage E, Brochard L; SRLF Collaborative Group on Mechanical Ventilation. Noninvasive versus conventional mechanical ventilation. An epidemiology survey. Am J Respir Crit Care Med 2001;63(4):874-880.
93. Doherty MJ, Greenstome MA. Survey of non-invasive ventilaton (NPPV) in patients with acute exacerbations of chronic obstructive pulmonary disease (COPD) in the UK. Thorax 1998;53(10):863-866.

94. Vanpee D, Delaunois L, Lheureux P, Thys F, Sabbe M, Meulemans A, et al. Survey of non-invasive ventilation for acute exacerbations of chronic obstructive pulmonary disease patients in emergency department in Belgium. Eur Emerg Med 2002;9(3):217-224.

95. Scala R, Naldi M. Ventilators for noninvasive ventilation to treat acute respiratory failure. Respir Care 2008;53(8):1054-1080.

96. Nava S, Navalesi P, Gregoretti C. Interfaces and humidification for non-invasive mechanical ventilation. Respir Care 2009;54(1):71-82.

97. Vignaux L, Vargas F, Roeseler J, Tassaux D, Thille AW, Kossowsky MP, et al. Patient-ventilator asynchrony during noninvasive ventilation for acute respiratory failure: a multicenter study. Intensive Care Med 2009;35(5):840-846.

98. Schettino P, Tucci R, Sousa R, Barbas V, Amato P, Carvalho R. Mask mechanics and leak dynamics during noninvasive pressure support ventilation: a bench study. Intensive Care Med 2001;27(12): 1887-1891.

99. Mehta S, McCool FD, Hill NS. Leak compensation in positive pressure ventilators: a lung model study. Eur Respir J 2001;17(2): 259-267.

100. Louis B, Leroux K, Isabey D, Fauroux B, Lofaso F. Effect of manufacturer-inserted mask leaks on ventilator performance. Eur Respir J 2010;35(3):627-636.

101. Olivieri C, Costa R, Conti G, Navalesi P. Bench studies evaluating devices for non-invasive ventilation: critical analysis and future perspectives. Intensive Care Med 2012;38(1):160-167.

102. Carteaux G, Lyazidi A, Cordoba-Izquierdo A, Vignaux L, Jolliet P, Thille AW, et al. Patient-ventilator asynchrony during noninvasive ventilation: a bench and clinical study. Chest 2012;142(2):367-376.

103. Scala R, Naldi M, Archinucci I, Coniglio G, Nava S. Noninvasive positive pressure ventilation in patients with acute exacerbations of COPD and varying levels of consciousness. Chest 2005;128(3): 1657-1666.

104. Díaz GG, Alcaraz AC, Talavera JC, Pérez PJ, Rodriguez AE, Cordoba FG, Hill NS. noninvasive positive-pressure ventilation to treat hypercapnic coma secondary to respiratory failure. Chest 2005; 127(3):952-960.

105. Scala R, Nava S, Conti G, Antonelli M, Naldi M, Archinucci I, et al. Noninvasive versus conventional ventilation to treat hypercapnic encephalopathy in chronic obstructive pulmonary disease. Intensive Care Med 2007;33(12):2101-2108.

106. Devlin JW, Nava S, Fong JJ, Bahhady I, Hill NS. Survey of sedation practices during noninvasive positive-pressure ventilation to treat acute respiratory failure. Crit Care Med 2007;35(10):2298-2302.

107. Constantin JM, Schneider E, Cayot-Constantin S, Guerin R, Bannier F, Futier E, et al. Remifentanil-based sedation to treat noninvasive ventilation failure: a preliminary study. Intensive Care Med 2007;33(1):82-87.

108. Rocco M, Conti G, Alessandri E, Morelli A, Spadetta G, Laderchi A, et al. Rescue treatment for non invasive ventilation failure due to interface intolerance with remifentanil analgosedation: a pilot study. Intensive Care Med 2010 36(12):2060-2065.

109. Crotti S, Lissoni A, Tubiolo D, Azzari S, Tarsia P, Caspani L et al. Artificial lung as an alternative to mechanical ventilation in COPD exacerbation. Eur Respir J 2012;39(1):212-215.

110. Kluge S, Braune SA, Engel M, Nierhaus A, Frings D, Ebelt H, et al. Avoiding invasive mechanical ventilation by extracorporeal carbon dioxide removal in patients failing noninvasive ventilation. Intensive Care Med 2012;38(10):1632-1639.

111. Nick Cave and the Bad Seed. Jesus on the moon. In: Dig, Lazarus, Dig!!! Mute-ANTI Records; 2008. 